\title{
Editorial: The Future and Directions of the Proceedings of the ASA
}

As requested by the Astronomical Society of Australia (ASA) through a motion at the 1994 Annual General Meeting, the Editorial Board of the Proceedings of the ASA (PASA) has considered the future and directions of the Proceedings after wide consultation with the Australian astronomical community. This editorial outlines the response from the community, which was on the whole very supportive, and details the decisions of the Editorial Board, which have been accepted by Council, which will govern the direction of this journal in the near future. Our thanks to those members of the community who took the time to respond to the questionnaire, and for the many helpful comments they made.

\section{The Response to the Questionnaire}

A questionnaire was sent to all individual members of the ASA $(\sim 320)$ and to about 20 non-members who had presented papers at the ASA meeting in Canberra in July 1994. The final number of responses was 69 , of which 65 were from members. A brief summary of the responses is given here.

Of the members, 57 felt that the journal should be continued in some form, two were ambivalent and six felt it should be discontinued. Of the non-members, all four were for the journal continuing in some form.

Those who were against a continuation at some level did not respond to the rest of the questionnaire, so the following responses are from the 57 members who felt it should continue.

- There was a very wide range of opinions as to what the level of the journal should be, from relegating it to a newsletter to taking on the Astrophysical Journal and becoming the leading astronomy journal in the world. The moderate position of keeping on at current levels/smali expansion was the favoured option.

- Most people felt that a change in name would be appropriate.

- Many felt that the current editorial policy of considering for publication any paper submitted should be continued.

- Many felt that papers from overseas should be considered if appropriate to Australian astronomy.

- A large number said we should maintain a high standard of refereeing.
On the whole there is a very wide range of opinions within the Australian astronomical community as to the standard of papers published in PASA and the standard of refereeing the papers get, ranging from 'all the papers are trivial and the refereeing is so poor as to be a waste of time', to 'some of the papers are definitely $A p J$ material and the refereeing is generally of a very high standard'. Until the community has a more uniform image of the journal, conflict over its future will continue.

\section{The Recommendations of the Editorial Board}

In a meeting on 21 October 1994, the Editorial Board considered the responses to the questionnaire, debated the issues at some length and made recommendations to the ASA Council regarding the future of the journal. These were accepted without major revision at the Council meeting on 24 November 1994, and are detailed below.

\section{Level of continuation}

The Editorial Board recommended that the journal continue at least at its present level-the journal will accept papers of interest to its Australian membership and the policy of accepting papers from other than the Annual Scientific Meeting will be publicised.

\section{Name of the journal}

As is apparent from the front cover, the name of the journal has been changed to Publications of the $A S A$, with the abbreviation $P A S A$ within the journal. When referring to $P A S A$ in other journals the recommended abbreviation is $P u b l$. Astron. Soc. Aust. Note that the International Standard Serial Number of the Publications has changed to $1323-3580$.

\section{Type of papers accepted for publication}

Papers will be accepted on the basis of scientific merit, and a paper submitted for publication should contain original and significant research, unless it is an invited review or historical article. The 'original and significant research' may be in the area of instrumentation or software development in an astronomical context without there being an appreciable amount of astronomy as such in the paper. A number of people who responded to the questionnaires commented on the difficulty of getting 
this type of paper accepted and on the importance of PASA continuing this tradition. The 1994 ASA ASM specifically included a session on astronomical software because Council saw this as a way (i) of informing the community of new developments and (ii) of drawing under the ASA umbrella those expert technical/software people who are normally overlooked at scientific meetings since they fall through the cracks.

Note that PASA will not accept papers in which most of the content has been published or submitted elsewhere.

Extended abstracts or papers from one- or twoday workshops being held in Australia are appearing more frequently in PASA. It has been decided that any request to publish the proceedings of conferences/workshops other than those organised by the ASA will be referred to the ASA Council for judgement, and that the request must come in sufficient time before the conference/workshop, typically a month, for a decision to be made and communicated to the conference/workshop.

\section{Refereeing}

As mentioned above, the perception of the quality of the refereeing ranges from abysmal to high. In order to set and maintain a high standard of refereeing, guidance will be given to referees in the form of a checklist similar to those provided by Astronomy $\&$ Astrophysics and Astrophysics 86 Space Science.

It was also decided that having two referees for each paper would be beneficial, and that, where necessary, one of the referees would be from overseas.

Any author/referee conflict will be adjudicated by an appropriate member of the Editorial Board, with his/her decision being final.

\section{Miscellaneous}

PASA has adopted the citation and reference style of the Astrophysical Journal $(A p J)$. Detailed information regarding this style may be found in $\S 1.9$ of the $A p J$ Instructions to Authors, in the first issue of every month for ApJ Part 1.

The use of keywords from the standard list used by most astronomical journals has been introduced. This list can be found with the $A p J$ annual index, and a list of no more than six is requested with each paper.

The received and accepted dates now appear above the abstract instead of after the references.

Large data papers will appear on CD-ROM, with only the text being printed in the paper version.

Society business, thesis abstracts, book reviews, membership lists, etc. will continue to appear in a separate section at the back of each volume. Membership lists will be published at least every two years.

Page charges will not normally be applied.

Volumes will now be numbered according to year and not after four issues as used to be the case. Hence this issue is 12(1) not 11(3), and next year we will start Volume 13 .

\section{Conclusion}

Some of these changes have already been implemented, such as the name change and the use of the $A p J$ reference style. However, it was felt that it would be unfair to introduce immediately those changes, such as the use of two referees, which change the ground rules, so to speak. These will be brought in with Volume 13 when everybody has had notice of the changes.

Electronic publishing was also discussed by the Editorial Board, and it was felt that inevitably $P A S A$ would head down this path, but that it would not happen for a couple of years yet.

Both the ASA Council and the Editorial Board are trying to raise the profile of $P A S A$. This will take time and effort and we appreciate your cooperation. 